
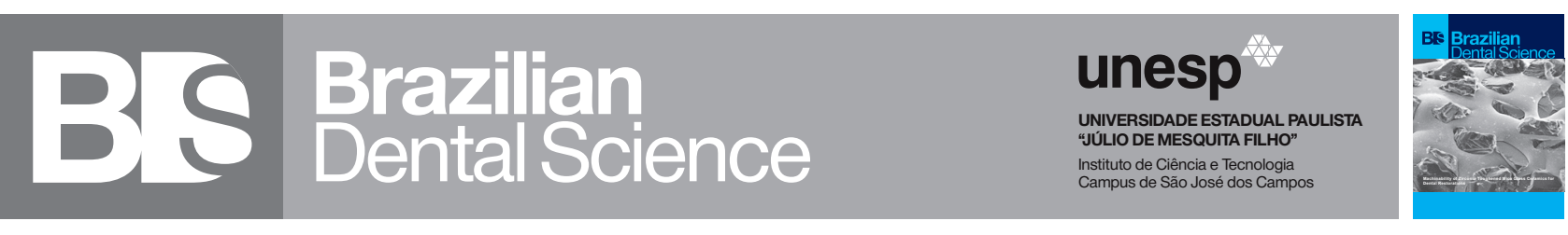

\title{
Basilar artery dolichoectasia an unusual and rare cause of secondary trigeminal neuralgia: a clinical report
}

\author{
Dolicoectasia da artéria basilar uma causa incomum e rara de neuralgia do trigêmeo secundária: um relato clínico \\ Zafar Ali KHAN ${ }^{1}$, Shammas Raza KHAN ${ }^{2}$, Tariq MEHMOOD ${ }^{3}$, Chaudhary Umar ASGHAR ${ }^{4}$, Naseer AHMED ${ }^{5}$ \\ 1 - Jouf University, College of Dentistry, Department Oral \& Maxillofacial Surgery, Kingdom, Saudi Arabia. \\ 2 - King Salman Specialist hospital, Kingdom, Saudi Arabia. \\ 3 - District Head Quarter Hospital Abbottabad, Pakistan. \\ 4 - Frontier Medical and Dental College, Pakistan. \\ 5 - Altamash Institute of Dental Medicine, Department of Prosthodontics, Pakistan.
}

\section{ABSTRACT}

Objective: Patients with Trigeminal Neuralgia often consults a dentist for relief of their symptoms as the pain seems to be arising from teeth and allied oral structures. Basilar artery Dolichoectasia is an unusual and very rare cause of secondary Trigeminal Neuralgia as it compresses the Trigeminal nerve Root Entry Zone. Case reports: We report three cases of Trigeminal Neuralgia caused by Basilar artery Dolichoectasia compression. The corneal reflex was found absent in all three of the cases along with mild neurological deficits in one case. Multiplanar T1/T2W images through the brain disclosed an aberrant, cirsoid (S-shaped) and torturous Dolichoectasia of basilar artery offending the Trigeminal nerve Root Entry Zone. Discussion: Based on these findings we propose a protocol for general dentist for diagnosis of patients with trigeminal neuralgia and timely exclusion of secondary intracranial causes. Conclusion: General dentists and oral surgeons ought to consider this diagnosis in patients presenting with chronic facial pain especially pain mimicking neuralgia with loss of corneal reflex or other neurosensory deficit on the face along with nighttime pain episodes. Timely and accurate diagnosis and prompt referral to a concerned specialist can have an enormous impact on patient survival rate in such cases.

\section{KEYWORDS}

Basilar artery; Cirsoid dolichoectasia; Corneal reflex; Trigeminal neuralgia.

\section{RESUMO}

Objetivo: Pacientes com Neuralgia do Trigêmeo frequentemente consultam um dentista para alívio de seus sintomas visto que a dor parece surgir dos dentes e estruturas orais relacionadas. A Dolicoectasia da artéria basilar é uma causa incomum e muito rara de Neuralgia do Trigêmeo secundária, pois comprime a zona de entrada da raiz do nervo trigêmeo. Relatos de casos: Relatamos três casos de Neuralgia do Trigêmeo causada por compressão por Dolicoectasia da artéria basilar. O reflexo da córnea se encontrava ausente em todos os três casos, juntamente com leves déficits neurológicos em um caso. Imagens multiplanares $\mathrm{T} 1 / \mathrm{T} 2 \mathrm{~W}$ através do cérebro revelaram uma Dolicoectasia cirsóide (em forma de S) anômala e tortuosa da artéria basilar que atingiu a zona de entrada da raiz do nervo trigêmeo. Discussão: Com base nesses achados, propomos para o dentista clínicogeral um protocolo para diagnóstico de pacientes com Neuralgia do Trigêmeo e exclusão oportuna de causas intracranianas secundárias. Conclusão: Os dentistas clínicos-gerais e cirurgiões orais devem considerar este diagnóstico em pacientes que apresentam dor facial crônica, especialmente dor que mimetiza neuralgia com perda do reflexo da córnea ou outro déficit neurossensorial na face junto com episódios de dor noturna. O diagnóstico oportuno e preciso e o encaminhamento imediato a um especialista em questão podem ter um enorme impacto na taxa de sobrevida do paciente em tais casos.

\section{PALAVRAS-CHAVE}

Artéria Basilar; Dolicoectasia cirsóide; Reflexo Corneano; Neuralgia do Trigêmeo. 


\section{INTRODUCTION}

$\mathrm{T}$ rigeminal neuralgia (TN) an episodic, electric-shock like pain in one or more branches of the fifth cranial nerve, is one of the most agonizing clinical entity that devastates the Quality of Life (QOL) of the patients, incapacitating their ability to speak, eat, drink, touch or wash the face and tooth brushing [1-3]. Reduced measures of daily functioning, quality of life, well-being, sleep, mood, and overall health status are directly associated with TN pain severity which affects employment in 34\% of patients [4].

The TN pain makes a patient to seek a dentist for management as it seems to be arising from teeth or oral structures [5]. It has been reported that $90 \%$ of the patient with $\mathrm{TN}$ like symptoms experienced pain for more than 1 year before receiving an accurate diagnosis, whereas $13 \%$ went 10 years without a diagnosis [2]. Misdiagnosis might lead to unnecessary procedures and can delay definitive treatment as it has been reported that about $33 \%$ to $65 \%$ of patients with trigeminal neuralgia (TN) appearing to their dentist initially undergoes unnecessary dental treatments $[1,2],[5,6]$.

Idiopathic trigeminal neuralgia is usually caused by intracranial neurovascular conflict and in $98 \%$ cases, the superior cerebellar artery (SCA) is the cause of compression at the trigeminal nerve root entry zone (TREZ) [1]. Basilar artery Dolichoectasia is an unusual and very rare cause of TN and is represented by a very small number of cases in literature [7-10]. We are reporting three cases of TN caused by Basilar artery Dolichoectasia.

\section{CASE REPORTS}

\section{Case No 1}

A 20-year-old male complained of electric shock-like pain in the prominence of the cheek for the last three years. He initially presented to a general dentist for management two years ago, mistaking it for toothache. Following a few unsuccessful dental procedures to relieve his pain, the patient was referred to an oral surgeon who performed neurectomy of the infra-orbital nerve to treat $\mathrm{TN}$. The pain recurred after one year. The patient presented six months after the recurrence. He was on Carbamazepine 200mg but admitted to being irregular in taking his medication as it did not provide any relief in his painful symptoms and made him very drowsy the whole day instead. On review of history, the patient complained of electric shock-like pain on the right side of the upper face with more than 10 painful episodes per day that would sometimes awaken the patient from sleep. On clinical examination and neurosensory testing, the corneal reflex was found absent. A magnetic resonance imaging (MRI) brain scan was advised that revealed an aberrant and torturous basilar artery in close contact at pons near the TREZ (Figure 1A). Based on the finding of MRI the patient was promptly referred to the neurosurgery department for vascular decompression. The patient successfully underwent decompression of the trigeminal nerve and remained pain-free up till two years of follow-up.

\section{Case No 2}

A 45-year-old male presented with severe stabbing pain on the right side of the face for the last five years. He had been to multiple general dentists for management of his pain and underwent many unsuccessful procedures including extractions and endodontic treatment. He had consulted a few oral surgeons who performed neurectomies that provided him with some temporary relief in pain. Currently, the patient was on carbamazepine $200 \mathrm{mg}$ and gabapentin 300mg without much relief. The pain episodes would awaken the patient from sleep and tormented him 15 to 20 times a day. Clinical examination revealed a mild neurosensory deficit on the face on the affected side along with the absence of corneal reflex. On MRI brain scan a note was made of a large Cirsoid (S-Shaped) basilar artery in the right cerebellopontine angle indenting the brainstem near the TREZ (Figure 1B). The patient was subsequently referred to the neurosurgery department for vascular decompression of the trigeminal nerve. Following 
the neurosurgical intervention, the patient had recovered all neurological functions and had no complaints of any pain or discomfort in the distribution of the trigeminal nerve for two years.

\section{Case No 3}

A 40-year-old female presented with lancinating pain in the right upper jaw for the last 4 years. She had consulted a general dentist for management of her symptoms who after performing a few unsuccessful dental procedures referred her to an oral surgeon. She had undergone a neurectomy for relief of pain but only to suffer recurrence after about 6 months. The patient was on carbamazepine 200 mg. On clinical examination, there was a mild neurosensory deficit in the infra-orbital region along with the weakness of the corneal reflex. Multiplanar imaging was done through brain acquiring T1/T2W images disclosing an aberrant dilated and elongated basilar artery offending the TREZ (Figure 1C) The patient was referred to the neurosurgery department for further management. Decompression of the trigeminal nerve was performed by the neurosurgeons. She was followed up for two years after her decompression and remained free from her trigeminal neuralgia.

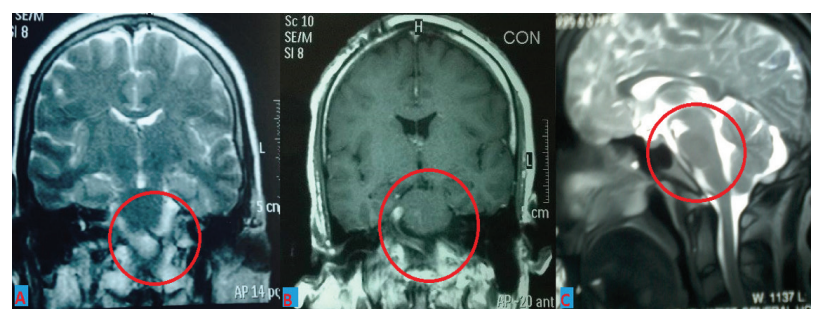

Figure 1 - Multiplanar T1/T2W images through brain disclosing an aberrant, cirsoid (S-shaped) torturous Dolichoectasia of basilar artery offending the TREZ. Patient No.1, 2 \& 3 as A, B and $\mathrm{C}$, respectively.

\section{DISCUSSION}

The basilar artery (BA) is formed by the unification of the two vertebral arteries (VAs) and extends on the basilar sulcus of the pons, from the bulbopontine sulcus to the interpeduncular or suprasellar cistern separating into the posterior cerebral arteries (PCAs), measuring approximately about $30 \mathrm{~mm}$ in length and 1.5 to $4 \mathrm{~mm}$ in width; an extension beyond these values indicates the presence of so-called "Dolichoectasia" a term derived from the Greek words: dolichos, meaning elongation, and ectasia, meaning dilatation of the BA11. It is a very rare cause of trigeminal neuralgia and is observed in approximately 2.8 to $7.7 \%$ of patients with vascular compression [7-10],[12]. Magnetic resonance imaging in our patient showed that the basilar artery was elongated as far as the cerebellopontine angle. According to Smoker et al, this is the most severe elongation of the basilar artery [13].

First detected by Dandy in 1934 as a cause of TN compressing the TREZ who used the term "cirsoid (S-shaped) aneurysms", emphasizing the elongation, tortuosity, and dilation of the artery with dense walls, in order to specify characteristic changes in the shape and dimensions of the vessel [14]. Later in 1945, he encountered 11 similar cases in 108 patients under-going posterior fossa exploration for treatment of trigeminal neuralgia [15]. One of our cases can be described as Cirsoid (S-shaped) as shown in Figure 1B.

Sunderland in 1948 reported two cases where the BA was elongated and was found to impress the trigeminal nerve out of 210 autopsies [16]. We found three cases of BA dolichoectasia in live patient and diagnosis was made by MRI brain scan.

Richard H Lye in 1986 presented of four patients, investigation of whom demonstrated the presence of an ectatic BA [7]. All the four case presented by Lye were aged above 50 years with one being as old as 82 years and two with histories of mild hypertension unlike our cases who were all below the age of 50 years with one presenting at an age of 20 years. All three of our cases were non-hypertensive but there was a consistent loss of corneal reflex in all of them.

The exact etiology of this condition is not completely understood; numerous potential origin hypothesis have been suggested including Hypertension-induced atherosclerosis, Congenital 
factors due to its reported association with various conditions like autosomal recessive polycystic kidney disease (ARPKD), Pompe disease, Fabry disease due to a novel mutation in the -galactosidase A (GLA) gene, sickle cell anemia, Marfan syndrome, Ehlers-Danlos syndrome, PHACES syndrome, Infectious diseases, including syphilis infection, varicella-zoster virus infection, Abnormal matrix metalloproteinase (MMP) expression associated with intracranial arterial dilation. The wide array of cases reported in literature suggest that the condition may be due to the combined effect of congenital and acquired factors [17]. This may explain the presentation of TN symptoms at a younger age.

This condition may present with widely variable clinical manifestations, with most common symptom being ischemic stroke, brainstem and cranial nerve compression, hydrocephalus, and cerebral hemorrhage. Thus the clinical features may be distributed under these four groups. The development of brainstem compression by VBD is usually slow considering its gradually progressive nature, with possible early detection of minor nerve damage having important clinical implication most commonly extended blink reflex latency and altered motor evoked potentials in limbs [18].

Practically any and all cranial nerve impairment symptoms can be associated, including most common compression of the trigeminal nerve root and facial nerve root presenting as trigeminal neuralgia, hemiface spasm respectively. Compression of abducens nerve, trochlear nerve, and oculomotor nerve has been reported in literature. Other symptoms such as nystagmus, tinnitus, hoarseness, and difficulty swallowing, dysarthria, ataxia, unilateral hemiparesis are significant to mention as they could raise the suspicion of presence of this pathology to the dental practitioners [17].
Noma and Kobayashi in 2009 reported three cases of TN due to vertebrobasilar dolichoectasia (VBD) presenting at their dental clinic and discussed the dental clinician's role in such cases emphasized that dentist must be aware of this particular cause of TN [19]. This fact can never be overemphasized as all three of our patients experienced pain for three, four and five years before receiving an accurate diagnosis and subsequent management for their symptoms.

The survival rate in VBD after 3 years follow-up was found to be $60 \%$ in a small case series by Ubogu and Zaidat [20]. Passero and Rossi in 2008 reported a relatively higher death rate following diagnosis of VBD as a natural history of the disease shows that such patients may experience a cerebrovascular event with high incidence after the initial diagnosis [21]. The cerebrovascular accident is significantly related to VBD severity, poor control of hypertension and the use of antiplatelet or anticoagulant drugs leading to increase the risk of hemorrhage [22]. This information is extremely crucial in-patient outcome with TN due to VBD as a potential tendency of clinicians to overvalue facial pain instead of dolichoectasia and its potential complication [23]. Timely and accurate diagnosis by the general dentist and /or the oral surgeon and prompt referral to a concerned specialist can have an enormous impact on patient survival rate in such cases.

Based on these findings we propose the following protocol for general dentist for diagnosis of patients with trigeminal neuralgia and timely exclusion of secondary intracranial causes of pain Figure 2. 


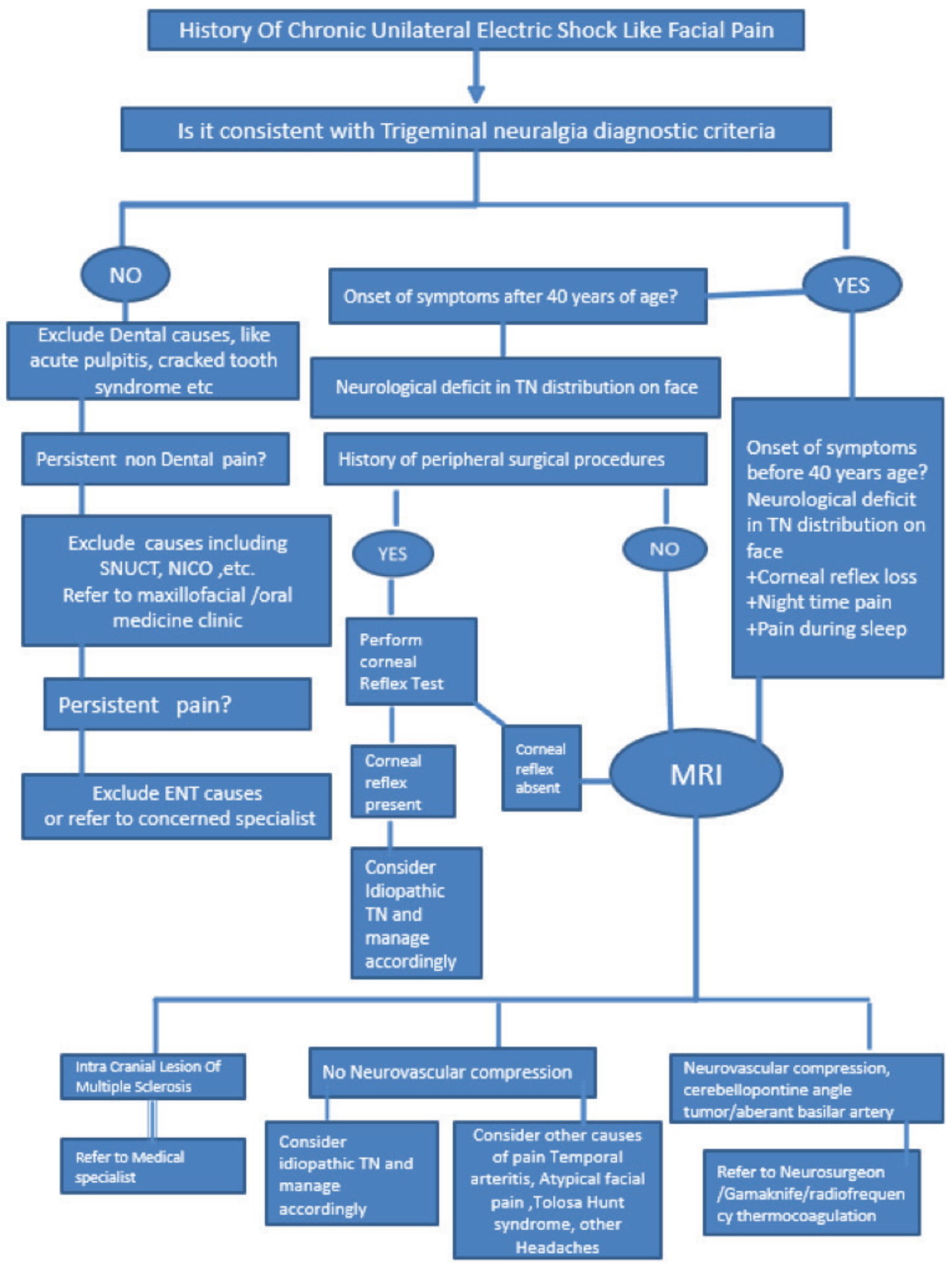

Figure 1- Protocol for general dentist for diagnosis of patients with trigeminal neuralgia and timely exclusion of secondary intracranial causes of pain. 
1. All patients presenting with chronic electric shock like unilateral facial pain must have detailed neurological examination to exclude any area of numbness on the face in the distribution of trigeminal nerve branches.

2. Since most of the patients with chronic TN like pain already have history of multiple surgical procedures including TN nerve branches neurectomy and alcohol injections and may present with pre-existing paresthesia of the face camouflaging actual neurological disturbance caused by any intra-cranial lesions, it is recommended to focus on the presence or absence of Corneal reflex in these cases.

3. Any patient with history of TN like pain commencing before 40 years age, occurring at night especially during sleep, and with absence of corneal reflex must undergo an MRI brain scan to exclude any intracranial lesion or anomaly in the TN nerve root entry zone and be referred promptly to concerned specialist for further management.

\section{CONCLUSION}

These three cases are an addition to the very few reported cases of TN due to VBD. General dentists and oral surgeons ought to consider this diagnosis in patients of TN presenting with loss of corneal reflex or other neurosensory deficit on the face along nighttime pain episodes. All patients presenting with TN like symptoms must undergo mandatory MRI brain scans to avoid delayed or erroneous diagnosis and unsuitable treatment interventions by their general dentists and oral surgeons.

\section{Acknowledgement}

The authors are grateful to College of dentistry, Jouf university, King Salman Specialist Hospital, Kingdom of Saudi Arabia, Altamash institute of dental medicine, Frontier dental college and District Headquarter Hospital, Pakistan for facilitation and support in this study.

\section{Ethical approval}

We confirm that the institutional review board provided ethical approval for this clinical report. We confirm that we have read the Helsinki Declaration and have followed their guidelines in this investigation.

\section{Conflict of interest statement}

We declare that conflict of interest does not exist.

\section{REFERENCES}

1. Ali M,Ansari SR, Khan MP,Rasool G. Microvascular decompression for idiopathic trigeminal neuralgia: ultimate solution to the management dilemma. PODJ2009:29(2):193-6.

2. Shah SA, Murad N, Salaar A. Trigeminal neuralgia: analysis of pain distribution. PODJ.2008;28:37-41

3. Zakrzewska JM. Differential diagnosis of facial pain and guidelines for management. Br J Anaesth. 2013 Jul;111(1):95-104. doi:101093/bja/aet125. PMID: 23794651.

4. Tölle T,DukesE, Sadosky A. Patient burden of trigeminal neuralgia: results from a cross-sectional survey of health state impairment and treatment patterns in six European countries. Pain Pract. 2006 Sep;6(3):153-60. doi: 10.1111/j.1533-2500.2006.00079.x. PMID: 17147591.

5. Baskaran K. A Systemic Review of Patients Appearing to Dental Professionals with Trigeminal Neuralgia Arising from Intracranial Tumours. IJSR. 2017:6(5):72-6.

6. Benoliel R, EliavE. Neuropathic orofacial pain. Oral Maxillofac Surg Clin North Am. 2008 May;20(2):237-54, vii. doi: 10.1016/j.coms.2007.12.001.PMID: 18343328

7. Lye RH. Basilar artery ectasia: an unusual cause of trigeminal neuralgia. $\mathrm{J}$ Neurol Neurosurg Psychiatry. 1986 Jan;49(1):22-8. doi: 10.1136/jnnp.49.1.22.

8. Miyazaki S, Fukushima T, Tamagawa T, Morita A. Trigeminal neuralgia due to compression of the trigeminal root by a basilar artery trunk. Neurol Med Chir (Tokyo). 1987;27(8):742-8. doi: 10.2176/nmc.27.742.

9. Takamiya Y, Toya S, Kawase T, Takenaka N, Shiga H. Trigeminal neuralgia and hemifacial spasm caused by a tortuous vertebrobasilar system. Surg Neurol. 1985 Nov;24(5):559-62. doi: 10.1016/0090-3019(85)90274-5.

10. Zhong J,Zhu J, Li ST, Guan HX. Microvascular decompressions in patients with coexistent hemifacial spasm and trigeminal neuralgia. Neurosurgery.2011 Apr;68(4):916-20; discussion 920. doi: 10.1227/NEU.0b013e318208f5ac.

11. VasovićL, Trandafilović M, Jovanović I,Ugrenović S, Vlajković S. Vertebral and/ or basilar dolichoectasia in human adult cadavers. Acta Neurochir (Wien). 2012 Aug;154(8):1477-88. doi:101007/s00701-012-1400-7.

12. Grigoryan YA, Sitnikov AR, Grigoryan GY. Trigeminal neuralgia and hemifacial spasm associated with vertebrobasilar artery tortuosity. Zh Vopr Neirokhir Im N NBurdenko. 2016;80(1):44-56. English, Russian. doi:10.17116/ neiro201680144-56.

13. Smoker WR, Price MJ, Keyes WD, Corbett JJ, Gentry LR. High-resolution computed tomography of the basilar artery: 1 . Normal size and position. AJNR Am J Neuroradiol. 1986 Jan-Feb;7(1):55-60. 
14. Dandy W. Concerning the cause of trigeminal neuralgia. Am J Surg. 1934;24(2):447-55. doi: 10.1016/s0002-9610(34)90403-7.

15. Dandy WE. Intracranial arterial aneurysms. Ithaca: Comstock Publishing; 1945.

16. Sunderland S. Neurovascular relations and anomalies at the base of the brain. J Neurol Neurosurg Psychiatry. 1948 Nov;11(4):243-57. doi: 10.1136/jnnp.11.4.243.

17. Yuan YJ, XUK, Luo Q, Yu JL. Research progress on vertebro-basilar Dolichoectasia. Int J Med Sci 2014; 11(10):1039-48. doi:10.7150/ijms.8566. http:// www.medsci.org/v11p1039.htm.

18. Passero S, Rossi S, Giannini F, Nuti D. Brain-stem compression in vertebrobasilar dolichoectasia. A multimodal electrophysiological study. Clin Neurophysiol. 2001Aug;112(8):1531-9. doi:10.1016/s1388-2457(01)00597-1.

19. Noma N, Kobayashi A, Kamo H, Imamura Y. Trigeminal neuralgia due to vertebrobasilar dolichoectasia: three case reports. Oral Surg Oral Med Oral Pathol Oral Radiol Endod. 2009 Sep;108(3):e50-5. doi:10.1016/j. triple0.2009.04.039.
20. Ubogu EE,Zaidat 00. Vertebrobasilar dolichoectasia diagnosed by magnetic resonance angiography and risk of stroke and death: a cohort study. J Neurol Neurosurg Psychiatry.2004 Jan;75(1):22-6.

21. Passero SG, Rossi S. Natural history of vertebrobasilar dolichoectasia. Neurology.2008 Jan 1;70(1):66-72. doi:10.1212/01.wnl.0000286947.89193.f3.

22. Passero SG, CalchettiB, Bartalini S. Intracranial bleeding in patients with vertebrobasilar dolichoectasia. Stroke. 2005 Jul;36(7):1421-5. doi:10.1161/01. STR.0000172311.64662.9c.

23. Campos WK, Guasti AA, da Silva BF, Guasti JA. Trigeminal Neuralgia due to Vertebrobasilar Dolichoectasia. Case Rep Neurol Med. 2012;2012:367304. doi: $10.1155 / 2012 / 367304$

\section{Dr Zafar Ali Khan}

\section{(Corresponding address)}

Jouf University, College of Dentistry, Department Oral \& Maxillofacial Surgery, King-

dom, Saudi Arabia.

E-mail: naprosthodontist@gmail.com

Date submitted: 2020 Jun 04

Accept submission: 2020 Aug 20 